\title{
Aerobic 2-ketogluconate metabolism of Klebsiella pneumoniae NCTC 418 grown in chemostat culture
}

\author{
Joost A. Simons, M. Joost Teixeira de Mattos and Oense M. Neijssel* \\ Department of Microbiology, Biotechnology Centre, University of Amsterdam, Nieuwe Achtergracht 127, \\ 1018 WS Amsterdam, The Netherlands
}

(Received 11 February 1991; revised 25 March 1991; accepted 18 April 1991)

\begin{abstract}
Klebsiella pneumoniae NCTC 418 is able to convert 2-ketogluconate intracellularly to 6-phosphogluconate by the combined action of an NADPH-dependent 2-ketogluconate reductase and gluconate kinase. Synthesis of the former enzyme was maximal under 2-ketogluconate-limited growth conditions. An instantaneous transition to a 2-ketogluconate-excess condition resulted in an acceleration of catabolism of this carbon source, accompanied by complete inhibition of biosynthesis. It is suggested that the cause of this inhibition resides in depletion of the NADPH pool due to the high rate at which NADPH is oxidized by 2-ketogluconate reductase.
\end{abstract}

\section{Introduction}

Klebsiella pneumoniae NCTC 418 , a member of the Enterobacteriaceae, is capable of oxidizing glucose extracellularly via the pyrroloquinoline quinone (PQQ)dependent glucose dehydrogenase (GDH) that oxidizes glucose to 1,4-gluconolactone (Neijssel et al., 1983). This compound can subsequently be hydrolysed either spontaneously or enzymically to gluconate (Jermyn, 1960; Hucho \& Wallenfels, 1972). Finally, gluconate can be oxidized to 2-ketogluconate by an FAD-dependent gluconate dehydrogenase (GADH) (Matsushita et al., 1982). Both GDH and GADH are membrane-bound enzymes.

Until now, little research has been done on the metabolism of the final oxidation product, 2-ketogluconate. It is assumed that Enterobacteriaceae catabolize 2-ketogluconate, after conversion into 6-phosphogluconate, by the subsequent action of 2-ketogluconate kinase (EC 2.7.1.63) and the NADPH-dependent 2-keto-6-phosphogluconate reductase (EC 1.1.1.69) via the Entner-Doudoroff pathway (De Ley, 1954; De Ley \& Vandamme, 1955; Frampton \& Wood, 1961 a). The same pathway is known to be active in a number of other microbial species (De Ley \& Vandamme, 1955; Ciferri \& Blakely, 1959; Frampton \& Wood, $1961 b$; Roberts et al., 1973), but in addition an NADPH-dependent 2-ketogluconate reductase - which reduces 2 -ketogluconate directly to gluconate - has been described for some acetic acid bacteria (Ameyama \& Adachi, 1982).

In this paper we report on the catabolism of 2-ketogluconate by $K$. pneumoniae NCTC 418 grown in chemostat culture under a variety of nutrient-limited conditions with 2-ketogluconate as the sole energy and carbon source. In addition, the effect of a sudden increase of the 2-ketogluconate concentration in carbonlimited cultures was investigated. As large amounts of 2-ketogluconate were needed for these experiments, a method was developed for the production of large quantities of 2-ketogluconate at low cost.

\section{Methods}

Micro-organism and growth conditions. Klebsiella pneumoniae NCTC 418 was maintained on tryptic meat-digest agar slopes. Organisms were cultured in a Porton-type chemostat (Herbert et al., 1965) with a working volume of approximately $350 \mathrm{ml}$. In order to obtain 2-ketogluconate-, potassium-, magnesium-, ammonia-, sulphate- or phosphate-limited growth conditions, simple salts media were used as specified by Evans et al. (1970), with minor modifications. Nitrilotriacetic acid $(2 \mathrm{mM})$ was used as chelator instead of citrate. Carbonlimited media contained 10-15 mM-2-ketogluconate; all other media contained 25-35 mM-2-ketogluconate to ensure steady-state concentrations of 2-ketogluconate above $10 \mathrm{mM}$ under potassium- $(0.2 \mathrm{~mm}$ $\mathrm{KCl}$ input), magnesium- $\left(0.039 \mathrm{mM}-\mathrm{MgCl}_{2}\right.$ input), ammonia- (6 mM$\mathrm{NH}_{4} \mathrm{Cl}$ input), sulphate- $\left(0.08 \mathrm{~mm}-\mathrm{Na}_{2} \mathrm{SO}_{4}\right.$ input) or phosphate$\left(0.1 \mathrm{~mm}-\mathrm{NaH}_{2} \mathrm{PO}_{4}\right.$ input) limitation. 2-Ketogluconate was sterilized by filtration (Seitz filter plates type EKS). The dilution rate $D$ was set at $0.30 \pm 0.02 \mathrm{~h}^{-1}$. The $\mathrm{pH}$ value of the culture was maintained automatically at a preset value $\pm 0 \cdot 1 \mathrm{pH}$ units, using sterile $2 \mathrm{M}-\mathrm{NaOH}$, and the temperature was maintained at $35^{\circ} \mathrm{C}$. To prevent excessive foaming silicone antifoaming agent $(\mathrm{BDH} ; 1 \%, \mathrm{w} / \mathrm{v})$ was added at a rate of approximately $0.5 \mathrm{ml} \mathrm{h}^{-1}$. Fully aerobic conditions were maintained throughout by injecting air at a rate of $24-301 \mathrm{~h}^{-1}$ into the region of the impeller, which was rotating at about 1500 r.p.m. 
Pulse experiments. The cultures were pulsed by injecting 5 or $10 \mathrm{ml}$ of a sterilized 2-ketogluconate solution $(500 \mathrm{~mm})$ into the culture vessel by means of a syringe. Simultaneously, the medium pump was switched off. Samples were taken at regular time intervals. The optical density was measured at $540 \mathrm{~nm}\left(\mathrm{OD}_{540}\right)$ (Ultrospec 4051 spectrophotometer; LKB); cells and supernatants were separated by centrifugation in an Eppendorf centrifuge. The supernatants were refrigerated to be analysed later. Oxygen consumption and carbon dioxide production were measured continuously during the experiment (see Analyses below). Growth rates were calculated from the $\mathrm{OD}_{540}$ and checked by measuring bacterial dry weight before the pulse and immediately after the excess 2-ketogluconate was completely consumed.

Shift-up experiments. At $t=0$ the dilution rate of a 2-ketogluconatelimited chemostat culture was increased by switching the medium pump to a higher rate. Oxygen consumption, carbon dioxide production and $\mathrm{OD}_{540}$ were measured as described above for the pulse experiment. Growth rates were calculated using the equation $\mu=D+t^{-1} \cdot \ln \left(X_{t}, X_{0}^{-1}\right)$, where $D$ is the new dilution rate and $X_{t}$ and $X_{0}$ are the biomass concentrations $\left(\mathrm{OD}_{540}\right)$ at the time of measurement and in steady state, respectively.

Preparation of 2-ketogluconate. Pseudomonas putida NCTC 10936 was grown in chemostat culture on a potassium-limited medium $(0.5 \mathrm{mM}-$ $\mathrm{KCl}$ input) according to Evans et al. (1970) at $\mathrm{pH} 6.5, D=0.3 \mathrm{~h}^{-1}$, temp. $=28^{\circ} \mathrm{C}$, with glucose as the carbon source $\left(30 \mathrm{~g}^{-1}\right.$ glucose input). Samples of this culture, mixed with $25 \%$ (v/v) glycerol, were stored at $-70^{\circ} \mathrm{C}$. To prepare 2 -ketogluconate, a batch of these cells was grown overnight in a 101 fermenter on the same medium at the same $\mathrm{pH}$ and temperature, but now with $20 \mathrm{~g}$ sodium gluconate $\mathrm{I}^{-1}$ as the carbon source. Cells were collected by centrifugation $(10 \mathrm{~min}$, $4200 \mathrm{~g}$ ) and suspended in $1012 \mathrm{~mm}$-sodium phosphate plus $500 \mathrm{~mm}$ sodium gluconate, $\mathrm{pH} 6.5$. This suspension was vigorously aerated and stirred at $28^{\circ} \mathrm{C}$. The $\mathrm{pH}$ value of the suspension was maintained automatically at pH $6.5 \pm 0.1$, using $2 \mathrm{M}-\mathrm{HCl}$. When all the gluconate was consumed, as determined enzymically by the method of Möllering \& Bergmeyer (1974), cells and debris were removed by centrifugation $(10 \mathrm{~min}, 4200 \mathrm{~g})$ and subsequent filtration (Seitz filter plates type EKS). In the supernatant no compounds other than 2-ketogluconate were detectable by HPLC (see Analyses below).

Preparation of cell-free extracts, membranes and the cytoplasmic fraction. Cell-free extracts were prepared according to Hommes et al. (1985). The buffer used throughout the preparation was $10 \mathrm{mM}$-sodium phosphate (pH 6.0) containing $5 \mathrm{mM}-\mathrm{MgCl}_{2}$. To separate membranes and the cytoplasmic fraction cell-free extracts were centrifuged for $1 \mathrm{~h}$ at $100000 \mathrm{~g}$.

Enzyme assays. Spectrophotometric assay of glucose dehydrogenase using Wurster's Blue as the electron acceptor was performed according to Hommes et al. (1985). Gluconate kinase was assayed according to Bergmeyer et al. (1974), as modified by Leegwater (1983). 2-Ketogluconate reductase was assayed in the following way. To a reaction

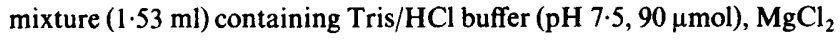
(6.5 $\mu \mathrm{mol})$, NADPH $(0.25 \mu \mathrm{mol})$ and cell-free extract $38 \mu \mathrm{mol} 2-\mathrm{keto}-$ gluconate (hemi-calcium salt) was added and the change in absorption at $340 \mathrm{~nm}$ was followed. From this change the rate of NADPH oxidation was calculated (molar extinction coefficient for NADPH $6.22 \times 10^{3} \mathrm{M}^{-1} \mathrm{~cm}^{-1}$ ). The assays were performed at $35^{\circ} \mathrm{C}$ with a Beckman DU 40 spectrophotometer. One Unit is defined as the amount of enzyme catalysing the conversion of $1 \mu \mathrm{mol}$ substrate $\min ^{-1}$. To measure the amount of gluconate produced per mol of NADPH oxidized in the 2-ketogluconate reductase assay, the protein in the reaction mixture was denatured with $3.5 \mathrm{M}$-perchloric acid $(100 \mu \mathrm{l})$. Subsequently, the mixture was neutralized with $7 \mathrm{M}$-potassium hydroxide $(50 \mu \mathrm{l})$ and centrifuged in an Eppendorf centrifuge for $2 \mathrm{~min}$. The gluconate concentration in the supernatant was determined enzymically by the method of Möllering \& Bergmeyer (1974).

Analyses. Bacterial dry weight was measured by the method of Herbert et al. (1971). Protein was determined according to Gornall et al. (1949). 2-Ketogluconate, acetate, pyruvate and lactate concentrations were determined by HPLC (LKB) with an Aminex HPX 87H organic acids column (Bio-Rad) at a temperature of $65^{\circ} \mathrm{C}$ with $5 \mathrm{mM}$ $\mathrm{H}_{2} \mathrm{SO}_{4}$ as eluent, using a 2142 refractive index detector (LKB) and an SP 4270 integrator (Spectra Physics). 2-Oxoglutarate was assayed according to Bergmeyer \& Bernt (1974). Oxygen consumed, and carbon dioxide produced by the cultures were determined by passing the gas from the fermenter through an oxygen analyser (Taylor Servomex type OA 272) and a carbon dioxide analyser (Servomex IR gas analyser PA 404).

\section{Results and Discussion}

To test whether $K$. pneumoniae NCTC 418 catabolizes 2-ketogluconate via the same pathway as described for some other members of the Enterobacteriaceae (De Ley, 1954; De Ley \& Vandamme, 1955; Frampton \& Wood, $1961 a)$ the combined activity of the 2-ketogluconate kinase and the 2-keto-6-phosphogluconate reductase was determined according to the method of Whiting et al. (1976) in a cell-free extract of $K$. pneumoniae NCTC 418, grown in batch culture with 2-ketogluconate as the sole carbon source $\left(\mathrm{pH} 6.8\right.$; temp. $\left.=35^{\circ} \mathrm{C}\right)$. NADPH was oxidized at a high rate when both ATP and 2-ketogluconate were present. However, as shown in Table 1, in the absence of ATP the same NADPH oxidation rate was observed. Because this result suggested the presence of an NADPH-dependent 2-ketogluconate reductase we investigated whether any gluconate was formed in the assay without ATP. This was indeed the case and the ratio of gluconate formed to NADPH consumed was approximately 1 (250 nmol gluconate formed and $260 \mathrm{nmol}$ NADPH consumed). No gluconate was

\section{Table 1. Total activities of several enzymes in cell-free extract, cytoplasm and membranes of $K$. pneumoniae NCTC 418 grown on 2-ketogluconate}

Cells were grown in batch culture on simple salts medium as specified by Evans et al. (1970), pH 6.8 with 2-ketogluconate $(10 \mathrm{~mm})$ as the carbon source. Total protein contents of cell-free extract, cytoplasmic fraction and membranes were, respectively, $11 \cdot 6,8 \cdot 0$ and $2 \cdot 6 \mathrm{mg}$.

\begin{tabular}{lccc}
\hline \hline & \multicolumn{3}{c}{ Enzyme activity (Units) } \\
\cline { 2 - 4 } & $\begin{array}{c}\text { Cell-free } \\
\text { extract }\end{array}$ & Cytoplasm & Membranes \\
\hline Glucose dehydrogenase & 1.34 & 0.065 & 1.48 \\
Gluconate kinase & 0.51 & 0.48 & 0.080 \\
2-Ketogluconate reductase & 0.28 & 0.24 & 0.025 \\
2-Ketogluconate reductase & 0.26 & 0.21 & 0.020 \\
$(3.2 \mu$ mol ATP added) & & & \\
\hline \hline
\end{tabular}


Table 2. Substrate utilization rates and product formation rates in chemostat cultures of $K$. pneumoniae NCTC 418 with 2-ketogluconate as the carbon source

Cells were grown at $D=0.3 \mathrm{~h}^{-1}, \mathrm{pH}$ 6.8. $q$, Specific rates expressed in $\mathrm{mmol} \mathrm{g}^{-1} \mathrm{~h}^{-1} . \% \mathrm{C}$, carbon recovery in \%. 2-KGA, 2-ketogluconate; HAc, acetate; 2-OG, 2-oxoglutarate.

\begin{tabular}{|c|c|c|c|c|c|c|}
\hline Limitation & $q_{2-\mathrm{KGA}}$ & $q_{\mathrm{O}_{2}}$ & $q_{\mathrm{CO}_{2}}$ & $q_{\mathrm{HAc}}$ & $q_{2-O G}$ & $\% \mathrm{C}$ \\
\hline Carbon & $3 \cdot 6$ & $7 \cdot 7$ & $10 \cdot 8$ & 0 & 0 & 102 \\
\hline Ammonium & $5 \cdot 1$ & $10 \cdot 8$ & $14 \cdot 6$ & 0 & 0.3 & 91 \\
\hline Sulphate & $5 \cdot 4$ & $12 \cdot 3$ & $16 \cdot 7$ & 0.8 & 0 & 91 \\
\hline Magnesium & $6 \cdot 1$ & $13 \cdot 6$ & $19 \cdot 1$ & 0.7 & 0.1 & 90 \\
\hline Phosphate & $5 \cdot 6$ & $11 \cdot 3$ & $17 \cdot 2$ & 0.6 & 0 & 89 \\
\hline Potassium & 7.8 & $24 \cdot 8$ & 30.9 & $2 \cdot 2$ & 0 & 100 \\
\hline
\end{tabular}

formed when NADPH was replaced by NADH and virtually all 2-ketogluconate reducing activity was located in the cytoplasm. In addition, significant gluconate kinase activity was detected in the cytoplasmic fraction of 2-ketogluconate-grown cells (Table 1). We conclude that the sequence of catabolic reactions by which $K$. pneumoniae NCTC 418 converts 2-ketogluconate (after the substrate is taken up) into 6-phosphogluconate is the opposite of the sequence described for Enterobacteriaceae by De Ley \& Vandamme (1955). In contrast to an initial phosphorylation reaction, in $K$. pneumoniae 2-ketogluconate is first reduced to gluconate by an NADPH-dependent 2-ketogluconate reductase. Subsequently, gluconate is phosphorylated to 6-phosphogluconate in a reaction catalysed by gluconate kinase.

To further study 2-ketogluconate metabolism in $K$. pneumoniae, this organism was grown in chemostat culture under various nutrient limitations. In contrast to glucose-sufficient conditions (Neijssel \& Tempest, 1976) $K$. pneumoniae excreted overflow products (acetate and/or 2-oxoglutarate) only at very low specific rates under 2-ketogluconate excess conditions. 2-Ketogluconate was mainly converted into $\mathrm{CO}_{2}$ and biomass (Table 2). In agreement with previous observations (Neijssel \& Tempest, 1976) the lowest specific rate of oxygen consumption $\left(q_{\mathrm{O}_{2}}\right)$ was found under carbonlimited conditions (Table 2), implying that under these conditions growth occurred with the highest efficiency with respect to energy metabolism. Under potassiumlimited conditions the highest $q_{\mathrm{O}_{2}}$ values were found, suggesting that potassium-limited growth puts a heavy energetic burden on these cells. One of the main reasons for this high energy requirement might be the energydependent uptake of ammonium ions by the highaffinity potassium uptake system $\mathrm{Kdp}$, followed by the efflux of intracellularly formed ammonia, to which compound the bacterial membrane is highly permeable. Such an energy-consuming ammonium cycle under
Table 3. 2-Ketogluconate reductase specific activities in chemostat cultures of K. pneumoniae NCTC 418 with 2-ketogluconate as the carbon source

Cells were grown at $D=0.3 \mathrm{~h}^{-1}, \mathrm{pH} \mathrm{6.8}$. Specific activities are expressed in Units (mg protein) ${ }^{-1}$.

\begin{tabular}{lc}
\hline \hline Limitation & 2-Ketogluconate reductase \\
\hline Carbon & 0.58 \\
Ammonium & $0 \cdot 10$ \\
Sulphate & 0.07 \\
Magnesium & 0.05 \\
Phosphate & 0.05 \\
Potassium & 0.12 \\
\hline \hline
\end{tabular}

potassium-limited conditions has been shown to be present in Escherichia coli (Buurman et al., 1991).

Cells were withdrawn from steady-state cultures and the in vitro 2-ketogluconate reductase activities were determined. Since standard assay conditions were applied these activities were considered to be a measure of the amount of enzyme synthesized. Synthesis of 2-ketogluconate reductase was found to be dependent on culture conditions: 2-ketogluconate-limited conditions resulted in activities in vitro that were much higher than under carbon-sufficient conditions (Table 3). This pattern of enzyme synthesis is characteristic for enzymes that are involved in the scavenging of the growthlimiting substrate (Meers et al., 1970; O'Brien et al., 1980; Streekstra et al., 1987).

Whereas under carbon-limited conditions the level of 2-ketogluconate reductase synthesis was highest, the specific rate of 2-ketogluconate consumption (and thus the flux through the 2-ketogluconate reductase) was found to be lowest. Therefore experiments were made to determine how carbon-limited cells reacted upon a sudden relief of the limitation. When excess 2-ketogluconate was added instantaneously to a 2-ketogluconate-limited culture (a so-called 'pulse'-experiment), the cells reacted by catabolizing this substrate at a highly elevated rate: when grown at $D=0.13 \mathrm{~h}^{-1}$ the specific 2-ketogluconate consumption rate was increased more than fivefold. It has been reported previously that such transitions often result in an instantaneous increase in catabolism without a corresponding increase in growth rate (Neijssel \& Tempest, 1976; Teixeira de Mattos et al., 1984). With 2-ketogluconate, an adverse effect on anabolism was observed: growth came to a complete standstill (Fig. $1 a$ ). It should be noted here that this phenomenon was found to occur not only at a culture $\mathrm{pH}$ of 6.8 and $D=0.13 \mathrm{~h}^{-1}$ as shown here, but also at other culture $\mathrm{pH}$ values ( $\mathrm{pH} \mathrm{5.5,} \mathrm{pH} \mathrm{8.0)}$ and dilution rates $\left(0.30 \mathrm{~h}^{-1}\right)$ tested. In all cases growth did not resume until the 2-ketogluconate concentration had decreased below a detectable level. Apparently, growth then 

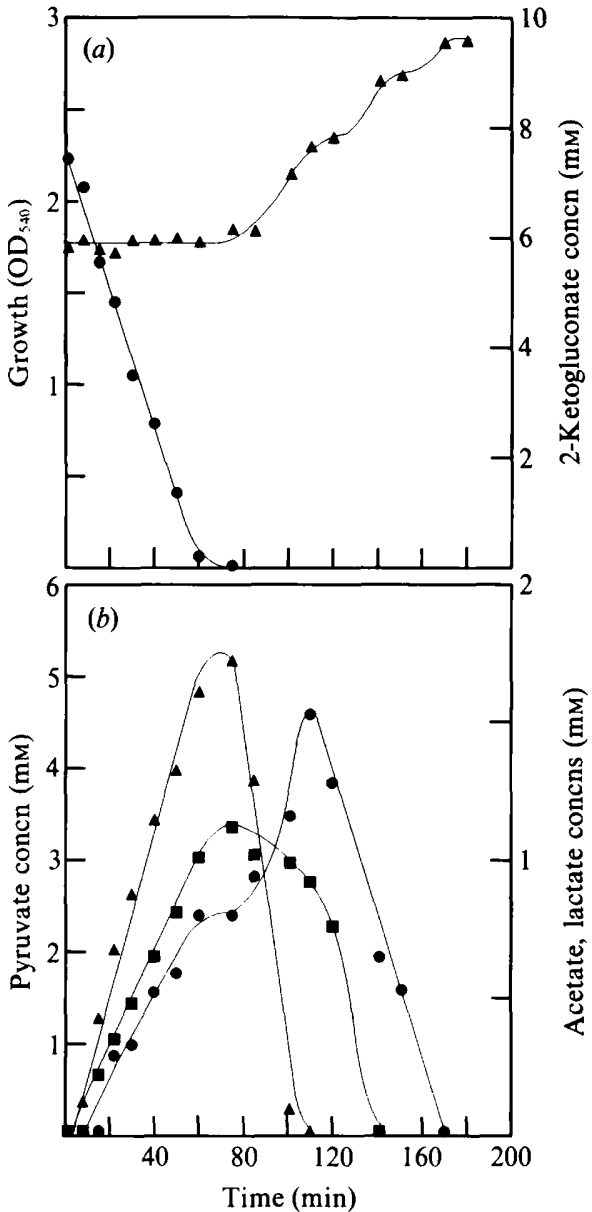

Fig. 1. Pulsing 2-ketogluconate to a 2-ketogluconate-limited chemostat culture of $K$. pneumoniae NCTC $418\left(D=0.13 \mathrm{~h}^{-1} ; \mathrm{pH} \mathrm{6.8)}\right.$. (a) Effect on consumption of 2-ketogluconate $(\bullet)$ and on growth $(\boldsymbol{\Delta}) ;(b)$ effect on production of pyruvate $(\boldsymbol{\Delta})$, lactate $(\boldsymbol{\square})$ and acetate $(\boldsymbol{\bullet})$

resumed on the products excreted during 2-ketogluconate catabolism (Fig. $1 a, b$ ).

Clearly, catabolism and anabolism were totally uncoupled during these transition periods. This metabolic behaviour must have serious energetic consequences for these cells: some form of energy dissipation must have taken place. One way to lower the amount of energy formed per 2-ketogluconate catabolized is to excrete partially oxidized endproducts. Indeed, after a 2-ketogluconate pulse, the energy source was not completely oxidized and overflow products were formed at high rate. Pyruvate was found to be the main product, but lactate was produced also (Fig. 1 b). This product is also formed under anaerobic conditions when a carbon-limited culture of $K$. pneumoniae NCTC 418 is suddenly relieved of its limitation. This has been ascribed to the activity of the methylglyoxal bypass (Teixeira de Mattos et al., 1984), a pathway that converts dihydroxyacetone phosphate to D-lactate without conservation of energy. Possibly the observed aerobic production of lactate is
Table 4. Effect on specific rate of substrate utilization and growth rate of a sudden increase in 2-ketogluconate concentration in a 2-ketogluconate-limited chemostat culture of K. pneumoniae NCTC 418

Cells were grown at $D=0.12 \mathrm{~h}^{-1}, \mathrm{pH} 6.8 . q_{\mathrm{KGA}}$, Specific 2-ketogluconate consumption rate in $\mathrm{mmol} \mathrm{g}^{-1} \mathrm{~h}^{-1} . \mu$, Growth rate in $\mathrm{h}^{-1}$.

\begin{tabular}{lccccc}
\hline \hline & $\begin{array}{c}\text { Steady } \\
\text { state }\end{array}$ & Pulse & $\begin{array}{c}D \rightarrow \\
0.22 \mathrm{~h}^{-1}\end{array}$ & $\begin{array}{c}D \rightarrow \\
0.43 \mathrm{~h}^{-1}\end{array}$ & $\begin{array}{c}D \rightarrow \\
0.78 \mathrm{~h}^{-1}\end{array}$ \\
\hline$q_{\mathrm{KGA}}$ & 1.9 & 10.4 & 3.4 & 6.6 & 9.4 \\
$\mu$ & 0.12 & 0 & 0.22 & 0.43 & 0 \\
\hline \hline
\end{tabular}

also the result of the functioning of this pathway. However, under aerobic conditions the bulk of the energy is generated by oxidative phosphorylation and a 2-ketogluconate-limited culture of $K$. pneumoniae NCTC 418 responded to a 2-ketogluconate pulse by increasing the oxygen consumption rate: when grown at $D=0.13 \mathrm{~h}^{-1}$ the specific oxygen consumption rate more than doubled. This suggests that after relief of the carbon limitation the efficiency of oxidative phosphorylation was strongly diminished and/or that the cells were able to spill the ATP produced at a high rate.

It should be realized that the first step in 2-ketogluconate catabolism is an NADPH-dependent reduction of this substrate. The explanation for the above phenomenon can be sought in the fact that NADPH also plays an important role in bacterial growth by delivering the reducing power for many biosynthetic processes. Thus, the sudden excess of 2-ketogluconate might have resulted in a depletion of the NADPH pool due to the presence of the elevated amount of 2-ketogluconate reductase present in carbon-limited cells. As a consequence, NADPH-dependent biosynthetic processes would be inhibited. Growth on excreted overflow products can resume only when the NADPH-consuming 2-ketogluconate catabolism comes to a standstill.

If this hypothesis is correct, cells should still be able to grow if the rate of 2-ketogluconate catabolism (and thus the rate of NADPH oxidation) is suddenly increased to a lesser extent than after a 2-ketogluconate pulse. To test this hypothesis, so-called 'shift-up' experiments were performed, in which the rate of 2-ketogluconate supply was increased by a chosen amount by suddenly increasing the dilution rate. The response of 2-ketogluconatelimited cultures of $K$. pneumoniae in such a shift-up experiment was dependent upon the magnitude of the shift-up (Table 4). As long as the cells were able to catabolize the 2-ketogluconate at the same rate at which it was supplied (i.e. the increase in catabolic rate was the same as the increase in dilution rate), they were still able to grow, even with an increased growth rate, and no 
products other than carbon dioxide and biomass were formed. When the dilution rate was increased to such an extent that the rate of 2-ketogluconate reduction was maximal, as in a pulse experiment, the cells reacted in the same way as after a 2-ketogluconate pulse: growth immediately stopped and other products, mainly pyruvate, were excreted.

When $K$. pneumoniae is grown anaerobically under glucose-limited conditions, relief of the limitation results in an increase in catabolism without a concomitant increase in the growth rate. The major part of the glucose is converted to D-lactate via the methylglyoxal bypass (Teixeira de Mattos et al., 1984). This behaviour has been explained as a consequence of the fact that under glucose-limited conditions the capacity of the first part of glycolysis is increased to a higher extent than the second part (Streekstra, 1990). This adaptation to carbonlimited conditions prevents expression of the anabolic overcapacity under sudden transitions to carbon source excess. The observations described in this work are another example of the adverse effects of adaptation to a specific growth condition.

\section{References}

AmeYama, M. \& ADACHI, O. (1982). 2-Keto-D-gluconate reductase from acetic acid bacteria. Methods in Enzymology 89, 203-210.

BERGMEYER, H. U. \& BERNT, E. (1974). $\alpha$-Ketoglutarat, UVspektrophotometrische Bestimmung. In Methoden der enzymatischen Analyse, 3rd edn, vol. II, pp. 1624-1627. Edited by H. U. Bergmeyer. Weinheim: Verlag Chemie.

Bergmeyer, H. U., Gawehn, K. \& Grassl, M. (1974). Enzyme als biochemische Reagentien. In Methoden der enzymatischen Analyse, 3rd edn, vol. I, p. 485. Edited by H. U. Bergmeyer. Weinheim: Verlag Chemie.

Buurman, E. T., Teixeira de Mattos, M. J. \& Neijssel, O. M. (1991). Futile cycling of ammonium ions via the high affinity potassium uptake system (Kdp) of Escherichia coli. Archives of Microbiology (in the Press).

CifERRI, O. \& Blakely, E. R. (1959). The metabolism of 2-ketoD-gluconate by cell-free extracts of Leuconostoc mesenteroides. Canadian Journal of Microbiology 5, 547-560.

DE LEY, J. (1954). Phospho-2-keto-D-gluconate, an intermediate in the carbohydrate metabolism of Aerobacter cloacae. Biochimica et Biophysica Acta 13, 302.

De LEY, J. \& VANDAMME, J. (1955). The metabolism of sodium 2-ketoD-gluconate by micro-organisms. Journal of General Microbiology 12. $162-171$.

Evans, C. G. T., Herbert, D. \& Tempest, D. W. (1970). The continuous cultivation of micro-organisms. II. Construction of a chemostat. Methods in Microbiology 2, 277-327.

Frampton, E. W. \& WoOD, W. A. (1961 $a$ ). Purification and properties of 2-ketogluconokinase from Aerobacter aerogenes. Journal of Biological Chemistry 236, 2578-2580.
Frampton, E. W. \& WoOD, W. A. (1961 b). Carbohydrate oxidation by Pseudomonas fluorescens. Journal of Biological Chemistry 236, 2571-2577.

Gornall, A. G., Bardawill, C. J. \& David, M. A. (1949). Determination of serum proteins by means of the biuret reaction. Journal of Biological Chemistry 177, 751-766.

Herbert, D., PhIPPS, P. J. \& Tempest, D. W. (1965). The chemostat: design and instrumentation. Laboratory Practice 14, 1150-1161.

Herbert, D., Phipps, P. J. \& Strange, R. E. (1971). Chemical analysis of microbial cells. Methods in Microbiology 5B, 209-344.

Hommes, R. W. J., van Hell, B., Postma, P. W., Neijssel, O. M. \& TEMPEST, D. W. (1985). The functional significance of glucose dehydrogenase in Klebsiella aerogenes. Archives of Microbiology 143 , 163-168.

HUCHO, F. \& WALLENFELS, K. (1972). Glucono- $\delta$-lactonase from Escherichia coli. Biochimica et Biophysica Acta 276, 176-179.

JERMYN, M. A. (1960). Studies on the glucono- $\delta$-lactonase of Pseudomonas fluorescens. Biochimica et Biophysica Acta 37, 78-92.

LEEGWATER, M. P. M. (1983). Microbial reactivity: its relevance to growth in natural and artificial environments, pp. 46-47. PhD thesis, University of Amsterdam, The Netherlands.

Matsushita, K., Shinagawa, E. \& AmeYama, M. (1982). D-Gluconate dehydrogenase from bacteria, membrane-bound. Methods in Enzymology 89, 187-193.

Meers, J., Tempest, D. W. \& Brown, C. M. (1970). 'Glutamine(amide):2-oxoglutarate amino transferase oxidoreductase (NADP)', an enzyme involved in the synthesis of glutamate by some bacteria. Journal of General Microbiology 64, 187-194.

MölleRING, H. \& BERGMEYER, H. U. (1974). D-Gluconat. In Methoden der enzymatischen Analyse, 3rd edn, vol. II, pp. 1288-1292. Edited by H. U. Bergmeyer, Weinheim: Verlag Chemie.

NeiJssel, O. M. \& TEMPEST, D. W. (1976). The role of energy-spilling reactions in the growth of Klebsiella aerogenes NCTC 418 in aerobic chemostat culture. Archives of Microbiology 110, 305-311.

Neijssel, O. M., Tempest, D. W., Postma, P. W., Duine, J. A. \& FraNK, JZN, J. (1983). Glucose metabolism by $\mathrm{K}^{+}$-limited Klebsiella aerogenes: evidence for the involvement of a quinoprotein glucose dehydrogenase. FEMS Microbiology Letters 20, 35-39.

O'Brien, R. W., Neijssel, O. M. \& Tempest, D. W. (1980). Glucose phosphoenolpyruvate phosphotransferase activity and glucose uptake rate of Klebsiella aerogenes growing in chemostat culture. Journal of General Microbiology 116, 305-314.

Roberts, B. K., Midgley, R. M. \& Dawes, E. A. (1973). The metabolism of 2-oxogluconate by Pseudomonas aeruginosa. Journal of General Microbiology 78, 319-329.

StreeKstra, H. (1990). Metabolic uncoupling in anaerobic Klebsiella pneumoniae. PhD thesis, University of Amsterdam, The Netherlands.

Streekstra, H., Teixeira de Mattos, M. J., Neijssel, O. M. \& TEMPEST, D. W. (1987). Overflow metabolism during anaerobic growth of Klebsiella pneumoniae NCTC 418 on glycerol and dihydroxyacetone in chemostat culture. Archives of Microbiology 147, $268-275$.

Teixeira de Mattos, M. J., Streexstra, H. \& Tempest, D. W. (1984). Metabolic uncoupling of substrate level phosphorylation in anaerobic glucose-limited chemostat cultures of Klebsiella aerogenes NCTC 418. Archives of Microbiology 139, 260-264.

Whiting, P. H., Midgley, M. \& Dawes, E. A. (1976). The role of glucose limitation in the regulation of the transport of glucose, gluconate and 2-oxogluconate, and of glucose metabolism in Pseudomonas aeruginosa. Journal of General Microbiology 92, 304-310. 